Article

\title{
Studies of Clinoptilolite-Rich Zeolitic Tuffs from Different Regions and Their Activity in Photodegradation of Methylene Blue
}

\author{
Jelena Pavlović ${ }^{1}\left(\mathbb{D}\right.$, Andraž Šuligoj ${ }^{2,3} \mathbb{D}$, Mojca Opresnik ${ }^{2}$, Nataša Novak Tušar ${ }^{2,4}$, Nataša Zabukovec Logar ${ }^{2,4} \mathbb{D}^{\mathbb{D}}$ \\ and Nevenka Rajić ${ }^{5, *}$
}

Citation: Pavlović, J.; Šuligoj, A.; Opresnik, M.; Tušar, N.N.; Logar, N.Z.; Rajić, N. Studies of

Clinoptilolite-Rich Zeolitic Tuffs from Different Regions and Their Activity in Photodegradation of Methylene Blue. Catalysts 2022, 12, 224. https:// doi.org/10.3390/catal12020224

Academic Editor: Lucian Baia

Publisher's Note: MDPI stays neutral with regard to jurisdictional claims in published maps and institutional affiliations.

Copyright: (c) 2022 by the authors. Licensee MDPI, Basel, Switzerland. This article is an open access article distributed under the terms and conditions of the Creative Commons Attribution (CC BY) license (https:// creativecommons.org/licenses/by/ $4.0 /)$.
1 Innovation Center of Faculty of Technology and Metallurgy, University of Belgrade, Karnegijeva 4, 11120 Belgrade, Serbia; jelena.pavlovic@tmf.bg.ac.rs

2 Department of Inorganic Chemistry and Technology, National Institute of Chemistry, Hajdrihova 19, SI-1001 Ljubljana, Slovenia; andraz.suligoj@ki.si (A.Š.); mojca.opresnik@ki.si (M.O.); natasa.novak.tusar@ki.si (N.N.T.); natasa.zabukovec@ki.si (N.Z.L.)

3 Faculty of Chemistry and Chemical Technology, University of Ljubljana, Večna pot 113, SI-1001 Ljubljana, Slovenia

4 Graduate School, University of Nova Gorica, Vipavska 13, SI-5000 Nova Gorica, Slovenia

5 Faculty of Technology and Metallurgy, University of Belgrade, Karnegijeva 4, 11120 Belgrade, Serbia

* Correspondence: nena@tmf.bg.ac.rs

\begin{abstract}
The present study focuses on clinoptilolite (CLI)-rich natural zeolitic tuffs and their photocatalytic activity in the degradation of cationic organic dyes. CLI from different regions was tested in the photocatalytic degradation of methylene blue (MB) as a model cationic dye. The photocatalytic tests were performed at room temperature and atmospheric pressure under visible light irradiation. For all the CLI samples, the highest activity was observed at $\mathrm{pH}=6$. Total $\mathrm{MB}$ degradation varied between 70 and $91 \%\left(C_{0}=10 \mathrm{mg} \mathrm{dm}^{-3}, 0.2 \mathrm{~g} \mathrm{dm}^{-3}\right.$ of photocatalyst, during $\left.300 \mathrm{~min}\right)$. It is suggested that the presence of Fe species in the studied tuffs is responsible for the photocatalytic activity. The activity increases linearly with the Fe content in the tuffs. The MB photodegradation follows the Langmuir-Hinshelwood kinetic model. The recyclability tests showed good stability and efficiency of the photocatalyst. The degradation rate decreased from 91 to $69 \%$ during three reaction cycles, indicating a promising potential of natural zeolites in the treatment of textile industry wastewater.
\end{abstract}

Keywords: clinoptilolite; natural zeolites; organic dyes; photocatalyst; photocatalytic activity

\section{Introduction}

With the increasing demand for some industrial products and the need for a higher standard of living, synthetic organic dyes have become indispensable in industries such as textiles, paper, printing, rubber, leather, cosmetics, and food. Organic dyes have complex structures and chemical stability; thus, their degradation is usually complicated. In addition, most dyes are toxic and carcinogenic, and their presence in water even at low concentrations causes severe environmental damage, including human health consequences [1-3]. Therefore, the removal of organic dyes from wastewater has become an important task for environmental protection. In addition to traditional water treatment technologies (such as adsorption, coagulation, flocculation, etc.), the development of new methods and materials that are more effective, environmentally friendly, and economical is a necessity.

Advanced oxidation processes (AOPs) are considered particularly effective for the removal of organic dyes from water media under mild reaction conditions. The high efficiency is attributed to the generation of highly reactive species, such as hydroxyl radicals, under radiation. These species interact with the dye molecules and cause their degradation and even mineralization [4,5]. 
Among AOPs, heterogeneous photocatalysis is one of the most promising methods. It is based on the irradiation of a semiconductor material/solid catalyst by visible or ultraviolet light. In this context, transition metals and their metal oxides (e.g., $\mathrm{TiO}_{2}, \mathrm{ZnO}$, $\mathrm{NiO}, \mathrm{CuO}, \mathrm{SnO}_{2}, \mathrm{Fe}_{2} \mathrm{O}_{3}$ ) have been frequently used as heterogeneous catalysts [6-9]. However, the use of these solids has many restrictions associated with environmental and practical aspects, such as high agglomeration tendency, separation problems, or metal leaching during the catalytic reaction. Deposition of photocatalytic particles on a suitable support has been regarded as effective for overcoming these difficulties. Different kinds of solids, such as activated carbon, carbon nanostructures, mesoporous silica, clays, and zeolites, have been investigated for this purpose [10-14]. Zeolites have also been considered as carriers of photocatalytic particles. Usually, synthetic zeolites, such as ZSM-5, Zeolite A, or zeolite Y [15-17], have been studied. The use of natural zeolites (especially the most abundant one-clinoptilolite) has recently attracted considerable attention [12,18]. Zeolites are crystalline open-framework aluminosilicates. They are built from tetrahedral $\left[\mathrm{SiO}_{4}\right]^{4-}$ and $\left[\mathrm{AlO}_{4}\right]^{5-}$ units, which are interconnected via corners in all three dimensions. Since the aluminosilicate lattice is negatively charged, the metal cations present in channels (or cages) provide electroneutrality. The metal cations (usually alkaline and earth alkaline) interact with the aluminosilicate lattice via electrostatic bonds. They are movable and can be readily replaced with other cations from water media. The ion exchange ability of zeolites enables them to be modified for different purposes [19]. Unique structural features of zeolites make them useful for adsorption in a variety of applications, including environmental protection, agriculture, and veterinary and human medicine [20-22].

Different metal oxide (MO) particles supported on the natural zeolite clinoptilolite (CLI) exhibit photocatalytic properties in the degradation of organic dyes $[18,23,24]$. It has been found that the photocatalytic efficiency of MO-CLI is even higher than that of pure MO. This was explained by a synergistic effect between the MO particles and the CLI lattice. The lattice prevents $\mathrm{MO}$ aggregation and also contributes to electron-hole recombination. The selected literature data are summarized in Table 1.

Table 1. Use of clinoptilolite in the photocatalytic degradation of different organic dyes.

\begin{tabular}{|c|c|c|c|c|c|c|}
\hline Catalyst & Dye & Irradiation Source & $\begin{array}{l}\text { Experimental } \\
\text { Conditions }\end{array}$ & $\begin{array}{l}\text { Degradation } \\
\text { Efficiency }\end{array}$ & Reusability & Ref. \\
\hline $\mathrm{TiO}_{2}-\mathrm{CLI}$ & Reactive Black 5 & 8 W UV lamp & $\begin{array}{c}0.4 \mathrm{~g} \mathrm{dm}^{-3}, 10 \mathrm{ppm} \\
\mathrm{pH}=6,500 \mathrm{~min}\end{array}$ & $86 \%$ & / & {$[23]$} \\
\hline $\mathrm{TiO}_{2}-\mathrm{CLI}$ & Acid orange 7 & $\begin{array}{c}30 \text { W UV-C Hg } \\
\text { lamp }\end{array}$ & $\begin{array}{l}80 \mathrm{~g} \mathrm{dm}^{-3}, 10 \mathrm{ppm} \\
90 \mathrm{~min}\end{array}$ & $85 \%$ & $67 \%$ after 4 cycles & [25] \\
\hline $\mathrm{ZnO}-\mathrm{CLI}$ & Bromothymol blue & 35 W Hg lamp & $\begin{array}{l}0.1 \mathrm{~g} \mathrm{dm}^{-3}, 4 \mathrm{ppm}, \\
\mathrm{pH}=7.8,300 \mathrm{~min}\end{array}$ & $80 \%$ & $48 \%$ after 3 cycles & [26] \\
\hline CuO-CLI & Methylene blue & 75 W Hg lamp & $\begin{array}{l}0.2 \mathrm{~g} \mathrm{dm}^{-3}, 7 \mathrm{ppm}, \\
\mathrm{pH}=5.9,180 \mathrm{~min}\end{array}$ & $61 \%$ & $28 \%$ after 4 cycles & [27] \\
\hline CuO-CLI & Bromophenol blue & & & $32 \%$ & $17 \%$ after 4 cycles & \\
\hline $\mathrm{SnO}_{2}-\mathrm{CLI}$ & Methylene blue & $\begin{array}{l}\text { Visible light lamp, } \\
\quad 8 \mathrm{~mW} \mathrm{~cm}^{-2}\end{array}$ & $\begin{array}{c}0.2 \mathrm{~g} \mathrm{dm}^{-3}, 10 \mathrm{ppm} \\
\mathrm{pH}=6,180 \mathrm{~min}\end{array}$ & $45 \%$ & $30 \%$ after 3 cycles & [24] \\
\hline CLI & Rhodamine B & $\begin{array}{l}100 \text { W LED Cool } \\
\text { daylight lamp }\end{array}$ & $\begin{array}{c}0.75 \mathrm{~g} \mathrm{dm}^{-3}, 4.8 \mathrm{ppm} \\
600 \mathrm{~min}\end{array}$ & $70 \%$ & $60 \%$ after 3 cycles & [28] \\
\hline
\end{tabular}

Surprisingly, it can be seen from Table 1 that pure CLI shows photocatalytic activity in the degradation of rhodamine B [28]. The authors explained this phenomenon by the presence of $\mathrm{Ti}$ and/or Fe species, which are usually found in small amounts, as impurities in zeolitic tuffs. Moreover, due to the unique structural properties of CLI, it could also be used for the catalytic degradation of organic dyes by Fenton-like oxidation reaction or for adsorption, as observed in other materials [29-31].

In previous studies of the photocatalytic activity of a $\mathrm{SnO}_{2}$-containing clinoptilolite [24], we found that the natural clinoptilolite from the Serbian deposit Slanci also exhibits photocatalytic activity in the degradation of methylene blue (MB). Taking all this into account, 
we now studied the photocatalytic performance of several zeolitic tuffs rich in CLI from deposits from different regions-Serbia, Turkey, Iran, Romania, and Slovakia. MB was selected as a model cationic dye. MB is a heterocyclic aromatic compound consisting of a chromophoric (N-S conjugated system on the central aromatic heterocycle) and auxochrome groups (N-containing groups with lone pair electrons on the benzene ring) $[32,33]$. It is one of the most commonly used organic dyes not only in dyeing processes but also for medical purposes. Therefore, a considerable amount of wastewater rich in MB is generated, which causes undesirable effects to human health, including respiratory distress, mental confusion, nausea, methemoglobinemia and/or skin irritation. Additionally, exceeded concentrations of MB in the water ecosystem lead not only to aesthetic undesirability, but also to blocking of light penetration, reduction of photosynthesis, and inhibition of plant growth. The photocatalytic performance was examined in the MB degradation at atmospheric pressure, room temperature, and under visible-light lamp irradiation. Degradation kinetics and recyclability of photocatalysts were also evaluated.

\section{Results and Discussion}

\subsection{Characterization}

PXRD analysis showed the presence of different mineral phases in the studied samples. Clinoptilolite was found to be the major mineral phase in all samples. A typical PXRD diffraction pattern is shown in Figure 1, for which the cation exchange capacity (CEC) is listed in Table 2. Clinoptilolite displays peaks at $2 \theta=9.8 ; 11.7 ; 12.8 ; 17.2 ; 19.1 ; 22.4$; 26.0; 29.9 and $32.3^{\circ}$ [34], which are marked on the diffractogram (Figure 1). Quantitative analysis confirmed the high content of CLI, which is in the range 75-85 wt.\%, depending on the type of deposit. The analysis also revealed the presence of: (a) albite and quartz in SCLI (14.6 and $4.4 \mathrm{wt}$ \%, respectively); (b) anorthite and quartz in TCLI (13.1 and $4.9 \mathrm{wt} . \%$, respectively); (c) quartz, anorthite, and calcite in $\operatorname{ICLI}(8.2,11.8$, and $4.6 \mathrm{wt}$.\%, respectively); (d) biotite and calcite in RCLI (6.7 and $8.4 \mathrm{wt} . \%$, respectively); and (e) anorthite and quartz in SKCLI (9.3 and $8.1 \mathrm{wt}$ \%, respectively).

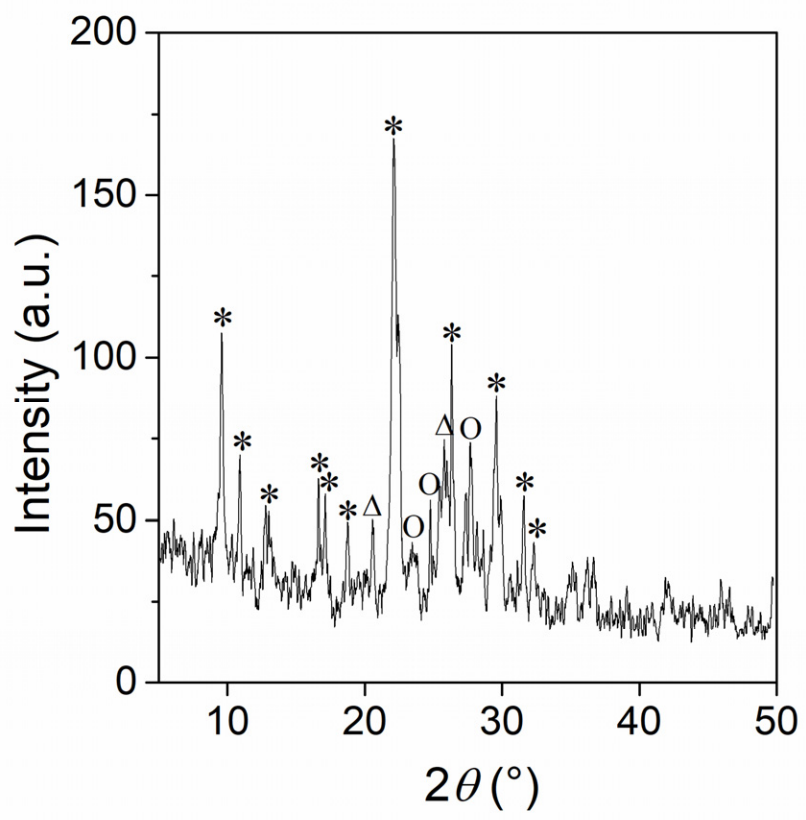

Figure 1. PXRD pattern of the zeolitic tuff (SCLI) $\left({ }^{*}\right.$ clinoptilolite, $^{\circ}$ albite and ${ }^{\Delta}$ quartz). The CEC values vary from 125.4 (TCLI) to 236.3 (RCLI) $\mathrm{mmol} \mathrm{M}^{+} / 100 \mathrm{~g}$. The chemical nature of the exchangeable cations differs, showing the effect of the type of deposits on the CLI chemical composition. It is also evident that conversion of SCLI to NaSCLI, $\mathrm{NH}_{4} \mathrm{SCLI}$ and HSCLI resulted in the enrichment of SCLI with $\mathrm{Na}^{+}, \mathrm{NH}_{4}{ }^{+}$, and $\mathrm{H}^{+}$, and in a significant decrease of the exchangeable cations in the CLI lattice. 
Table 2. Cation exchange capacity (CEC) of the samples.

\begin{tabular}{cccccc}
\hline \multirow{2}{*}{ Sample } & $\mathbf{N a}^{+}$ & $\mathbf{K}^{+}$ & $\mathbf{C a}^{\mathbf{2 +}}$ & $\mathbf{M g}^{\mathbf{2 +}}$ & $\sum$ \\
\cline { 2 - 6 } & \multicolumn{5}{c}{ Concentration $\mathbf{( m \mathbf { m o l ~ M }} \mathbf{~} \mathbf{1 0 0} \mathbf{~ g )}$} \\
\hline SCLI & 18.6 & 11.2 & 118.9 & 34.2 & 182.9 \\
TCLI & 4.3 & 25.5 & 79.8 & 15.8 & 125.4 \\
SKCLI & 3.6 & 45.1 & 86.9 & 5.3 & 140.9 \\
RCLI & 5.2 & 50.6 & 173.7 & 6.8 & 236.3 \\
ICLI & 59.8 & 21.8 & 44.6 & 3.5 & 129.7 \\
NaSCLI & 188.3 & 5.7 & 18.9 & 2.9 & 215.8 \\
$\mathrm{NH}_{4}$ SCLI & 0.6 & 1.5 & 10.9 & 16.0 & 29.0 \\
HSCLI & 3.2 & 7.3 & 2.8 & 1.5 & 14.8 \\
\hline
\end{tabular}

Thermal behavior of the samples is similar. A typical thermogram is shown in Figure 2. Total weight loss occurs up to $800{ }^{\circ} \mathrm{C}$ and varies from about 8.0 (ICLI) to $14.6 \mathrm{wt} . \%$ (RCLI), depending on the deposit. The weight loss is accompanied by several DTG maxima, indicating that the water loss is not continuous; this is due to the presence of water molecules at different crystallographic sites inside the CLI lattice.

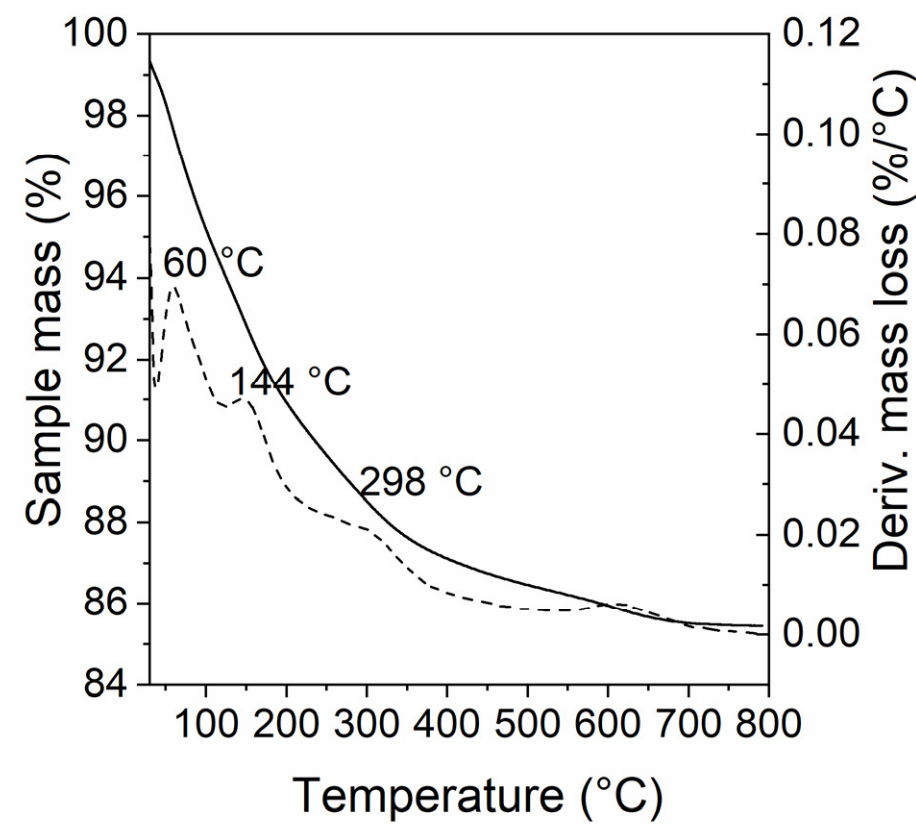

Figure 2. SCLI thermogram (solid line-TG curve and dashed line-DTG curve).

The surface morphology of the samples was studied using SEM analysis. As can be seen from Figure 3, the samples mainly contain plate crystals belonging to CLI.

Textural properties obtained from the nitrogen adsorption/desorption isotherms are given in Table 3. The results are in agreement with the reports of other research and suggest that differences in porosity are due to different deposits [35,36]. It is evident that the specific surface area $\left(S_{\mathrm{BET}}\right)$ varies from 23.0 to $45.1 \mathrm{~m}^{2} \mathrm{~g}^{-1}$ and $V_{\text {mic }}$ from 0.0978 to $0.1357 \mathrm{~cm}^{3} \mathrm{~g}^{-1}$. Moreover, there is no significant change in $S_{\mathrm{BET}}$ after the conversion of SCLI to NaSCLI and $\mathrm{NH}_{4} \mathrm{SCLI}$ in contrast to the conversion to HSCLI $\left(S_{\mathrm{BET}}\right.$ increases from 23.0 to $33.0 \mathrm{~m}^{2} \mathrm{~g}^{-1}$ ). The increasing values can be explained by a partial dealumination during the conversion of SCLI to HSCLI. Dealumination of the aluminosilicate lattice leads to the opening of the pores [35-37] and can increase the specific surface area. 

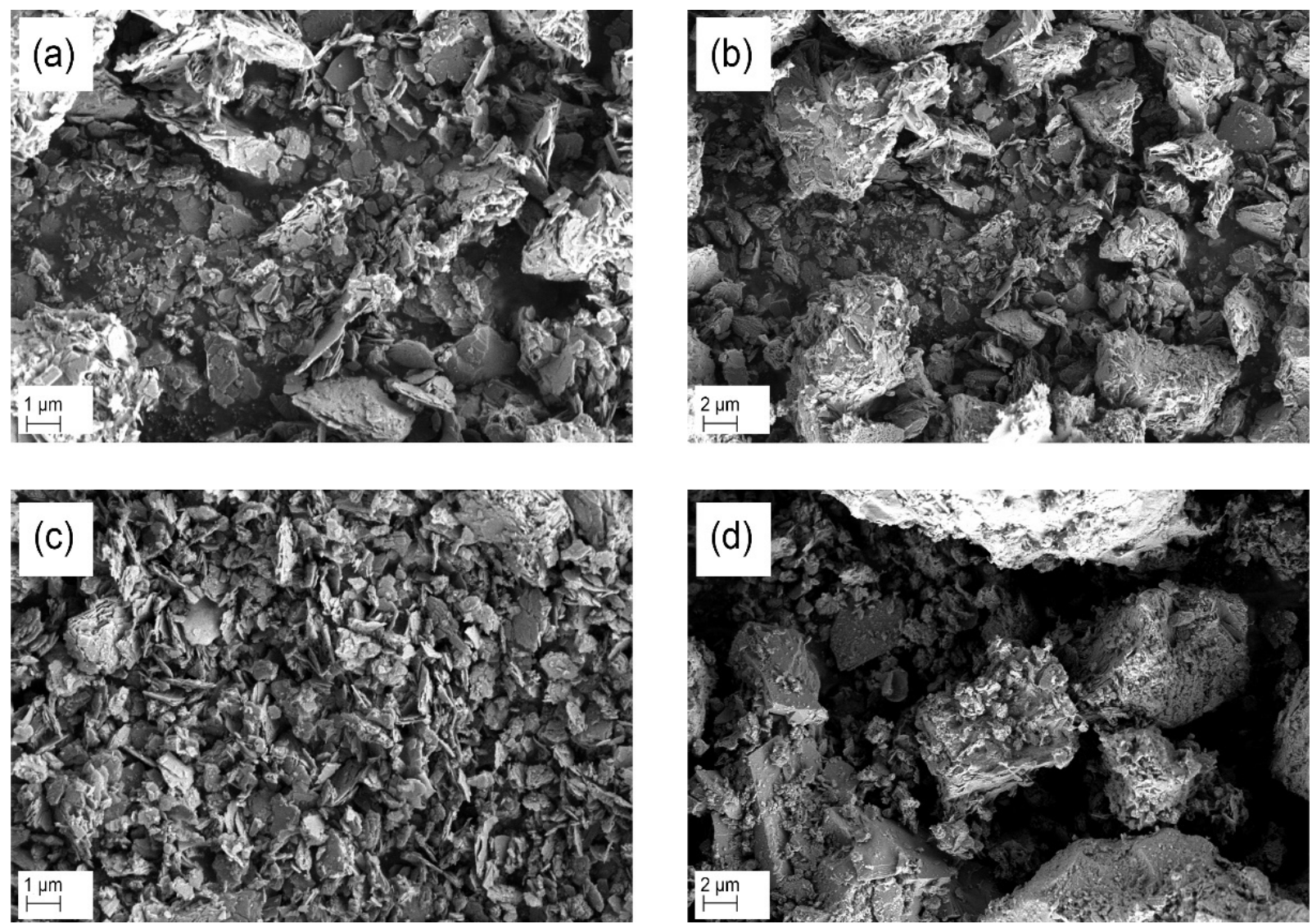

Figure 3. SEM images of SCLI (a,b) and TCLI (c,d).

Table 3. Textural properties of the samples.

\begin{tabular}{|c|c|c|c|c|c|c|c|}
\hline Sample & $S_{\mathrm{BET}}{ }^{1}, \mathrm{~m}^{2} \mathrm{~g}^{-1}$ & $\begin{array}{l}S^{2} \text { Lang, } \\
\mathrm{m}^{2} \mathrm{~g}^{-1}\end{array}$ & $S_{\text {mic }}{ }^{3}, \mathrm{~m}^{2} \mathrm{~g}^{-1}$ & $S_{\mathrm{ext}}{ }^{4}, \mathrm{~m}^{2} \mathrm{~g}^{-1}$ & $V_{\mathrm{mic}}{ }^{5}, \mathrm{~cm}^{3} \mathrm{~g}^{-1}$ & $V_{\mathrm{t}}^{6}, \mathrm{~m}^{3} \mathrm{~g}^{-1}$ & $D^{7}, \mathrm{~nm}$ \\
\hline SCLI & 23.0 & 36.8 & 0.7259 & 22.2656 & 0.1335 & 0.1361 & 19.4 \\
\hline TCLI & 45.1 & 72.3 & 4.3185 & 40.7610 & 0.1217 & 0.1253 & 8.3 \\
\hline SKCLI & 25.1 & 40.4 & 1.5393 & 23.5839 & 0.1357 & 0.1379 & 17.8 \\
\hline RCLI & 35.1 & 56.2 & 3.0254 & 32.0343 & 0.0978 & 0.1004 & 8.5 \\
\hline ICLI & 25.8 & 41.7 & 1.3850 & 24.4316 & 0.1303 & 0.1323 & 17.8 \\
\hline HSCLI & 33.0 & 50.6 & 8.6373 & 24.3537 & 0.1315 & 0.1361 & 19.4 \\
\hline $\mathrm{NH}_{4} \mathrm{SCLI}$ & 24.8 & 40.0 & 0.3504 & 24.4839 & 0.1088 & 0.1116 & 15.9 \\
\hline NaSCLI & 23.5 & 37.5 & 1.6290 & 21.9144 & 0.1004 & 0.1030 & 16.1 \\
\hline
\end{tabular}

${ }^{1}$ specific surface area based on the BET theory determined in the $p / p_{0}$ range corresponding to the increasing trend of the Rouquerol plot; ${ }^{2}$ Langmuir surface area; ${ }^{3}$ micropore surface area based on the $t$-plot analysis; ${ }^{4}$ external surface area $S_{\mathrm{BET}}-S_{\text {mic }} ;{ }^{5}$ micropore volume based on the $t$-plot analysis; ${ }^{6}$ total pore volume based on the BJH adsorption analysis; ${ }^{7}$ average pore size based on the BJH desorption analysis.

The nitrogen adsorption/desorption isotherms are given in Figure 4. Based on the IUPAC classification, the samples exhibit the adsorption isotherm of type IV that is typical for zeolites with both micropores (derived from structural features of the lattice) and mesopores formed by zeolite modification. In addition, the presence of a hysteresis loop of type H3 (in the range $p / p_{0}=0.5-1$ ) is characteristic of tuffs rich in clinoptilolite, and it can be attributed to multilayer adsorption and capillary condensation either in mesopores of impurities (such as feldspar, quartz, etc.) or in the space between zeolite crystallites [38]. 

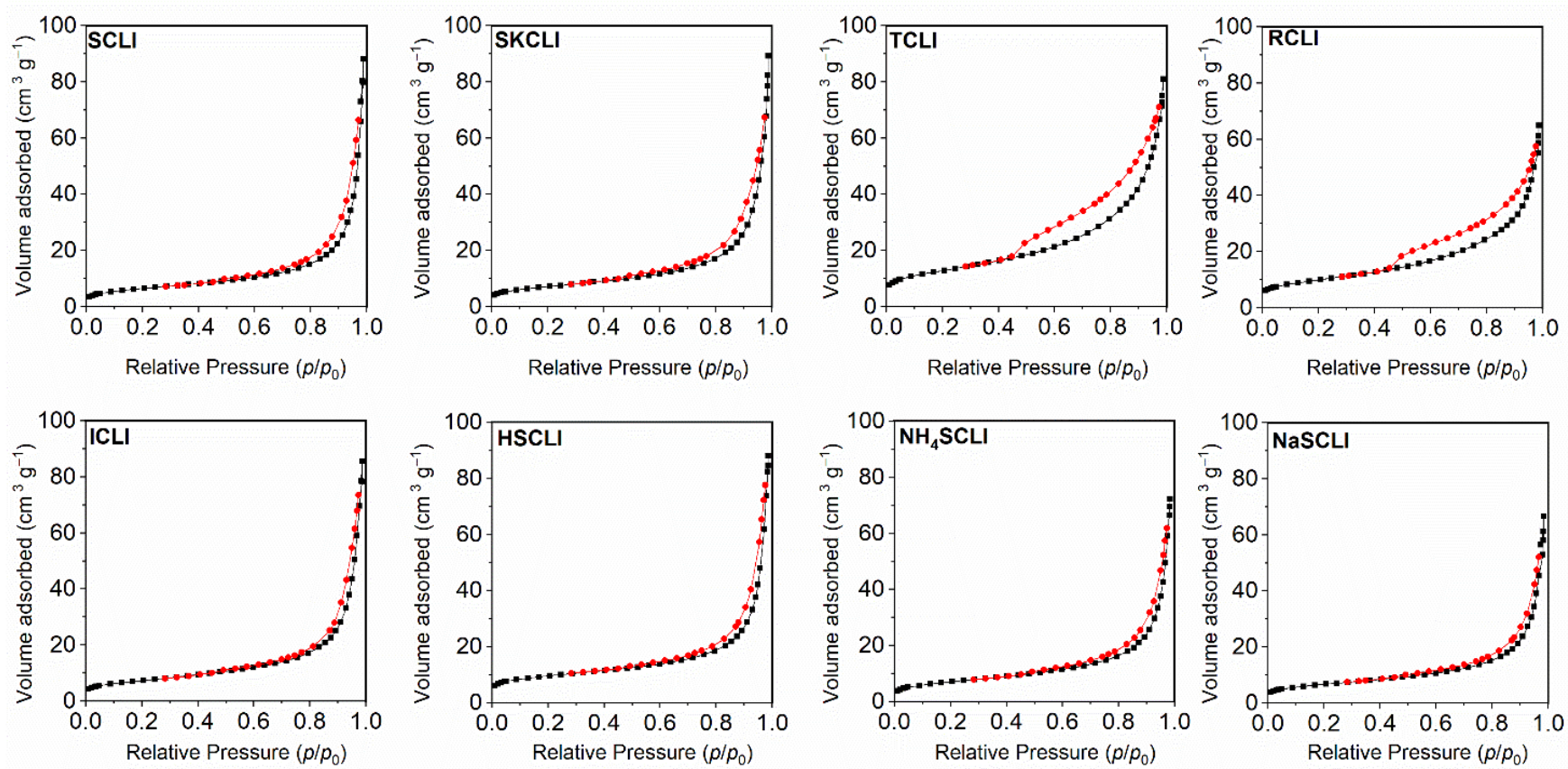

Figure 4. Adsorption/desorption isotherms of nitrogen at $-196^{\circ} \mathrm{C}$ on the used samples.

\subsection{Photocatalytic Tests}

Photodegradation of aqueous solutions of $\mathrm{MB}\left(C_{0}=10 \mathrm{mg} \mathrm{dm}^{-3}\right)$ was performed under irradiation with visible light (Figure 5). Since $\mathrm{pH}$ is one of the most important factors of photodegradation, photocatalytic tests were performed at different $\mathrm{pH}$ values (3, 6, and 9).

The blank tests demonstrated that the degradation extent of MB in the absence of photocatalyst is almost negligible. The presence of the zeolitic samples leads to a high degradation rate (Figure 5).

Before irradiation, suspensions were shaken in the dark for $30 \mathrm{~min}$ to reach the adsorption/desorption equilibrium. As shown in Figure 5, adsorption of MB onto zeolitic tuffs varies most probably due to differences in the specific surface area. The higher specific surface area provides more adsorption active sites and accordingly a higher extent of MB adsorption. Additionally, for all tested samples, MB adsorption increased with $\mathrm{pH}$. This can be explained by the fact that for a cationic dye, such as MB, competition for adsorption sites occurs between hydrogen ions and $\mathrm{MB}$ cations. In an acidic medium $(\mathrm{pH}=3), \mathrm{MB}$ adsorption is lowest. With increasing $\mathrm{pH}, \mathrm{MB}$ adsorption increases due to strong electrostatic attractions between $\mathrm{MB}$ and CLI surfaces.

MB degradation under visible light irradiation is also affected by $\mathrm{pH}$. Figure 5 shows that $\mathrm{MB}$ degradation notably increases by increasing $\mathrm{pH}$ from 3 to 6 . A slowdown in photocatalytic activity is evident at $\mathrm{pH}=9$. Thus, the best photocatalytic activity for all tested zeolitic tuffs was found to be at $\mathrm{pH}=6$. At $\mathrm{pH}=6$, the $\mathrm{MB}$ degradation rate varies from about $36 \%$ (ICLI) to $47 \%$ (TCLI), whereas the MB total degradation is from $70 \%$ (SCLI) to $91 \%$ (TCLI).

The total degradation of MB through the photocatalytic process applied in this study can be attributed to a joint effect of initial adsorption and degradation under irradiation with visible light. The adsorption values suggest that an important feature of the zeolitebased photocatalyst is MB adsorption during the dark phase. The adsorption most probably occurs via the ion-exchange mechanism since at $\mathrm{pH}=6 \mathrm{MB}$ is present in cationic form. The ion exchange takes place at the surface of CLI due to the steric effect caused by the large diameter of $\mathrm{MB}^{+}(1.43 \times 0.61 \times 0.4 \mathrm{~nm})$. The $\mathrm{MB}$ diameter exceeds the dimensions of the openings at the entrance to the clinoptilolite lattice $(0.65 \times 0.70 \mathrm{~nm})$, and MB replaces only the surface cations $[39,40]$. The interactions between $\mathrm{MB}$ and the aluminosilicate lattice are strong since $\mathrm{MB}^{+}$cannot be replaced by other cations (results are not shown). Namely, 
regeneration of spent zeolites usually includes treatment with $\mathrm{NaCl}$ solution. The treatment in this case was not successful, and the regeneration of the spent adsorbents was done by calcination.
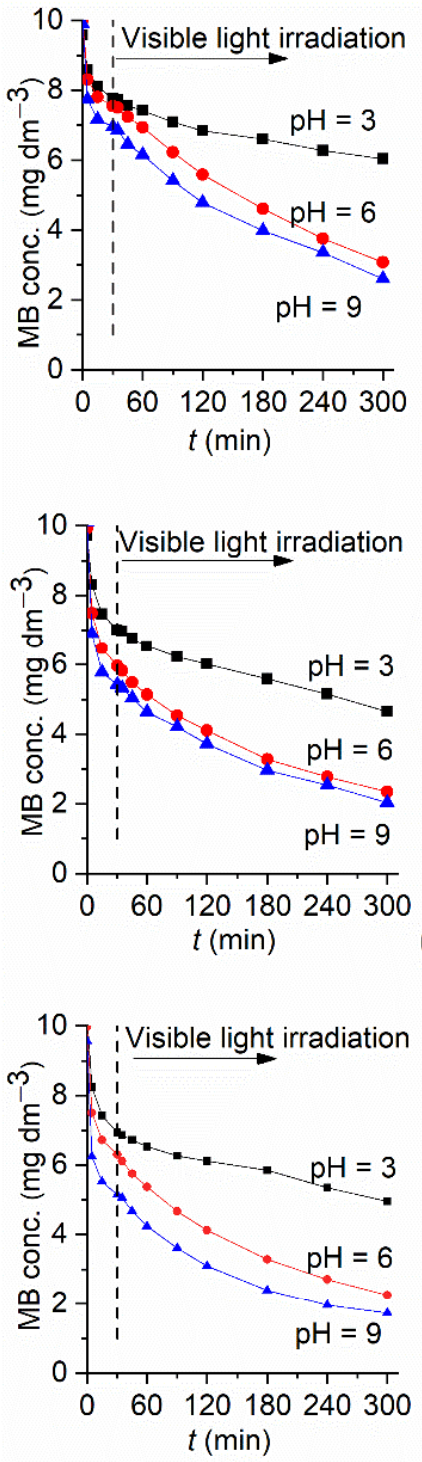

(c)
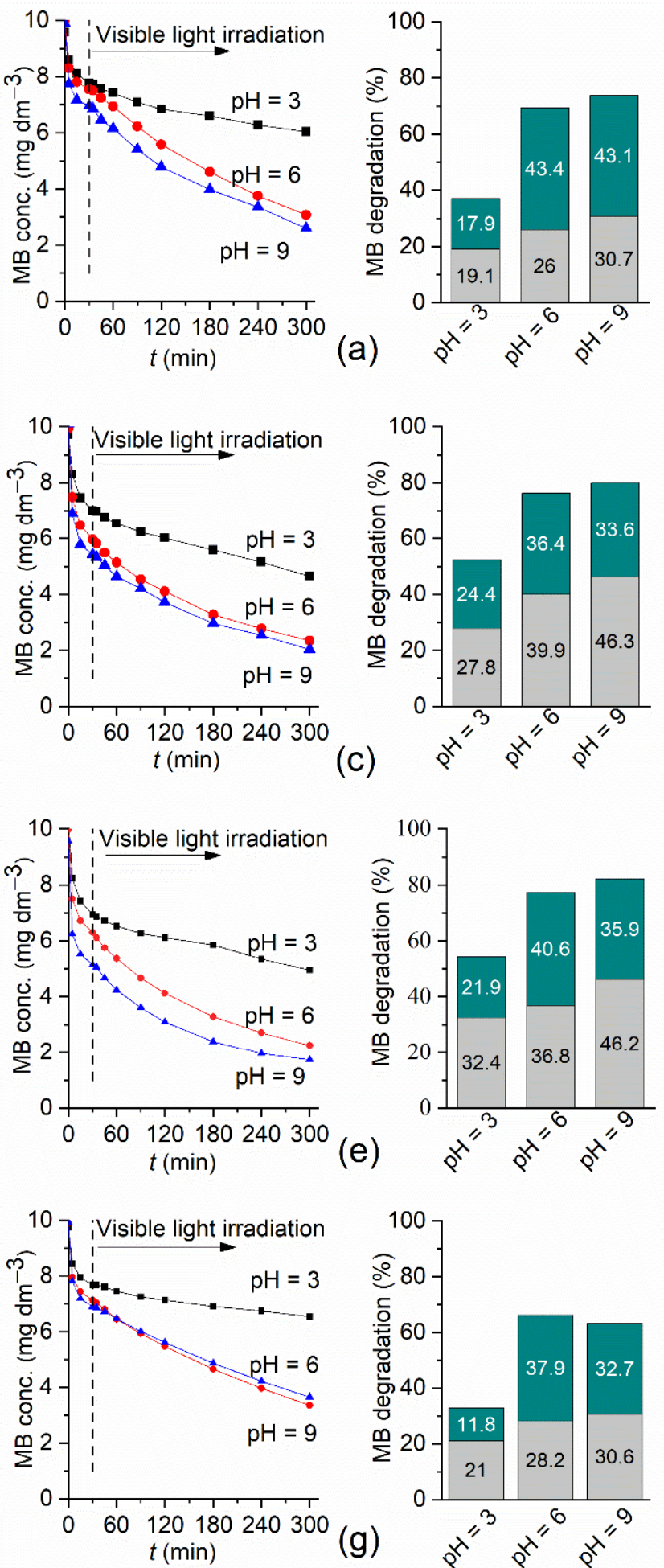
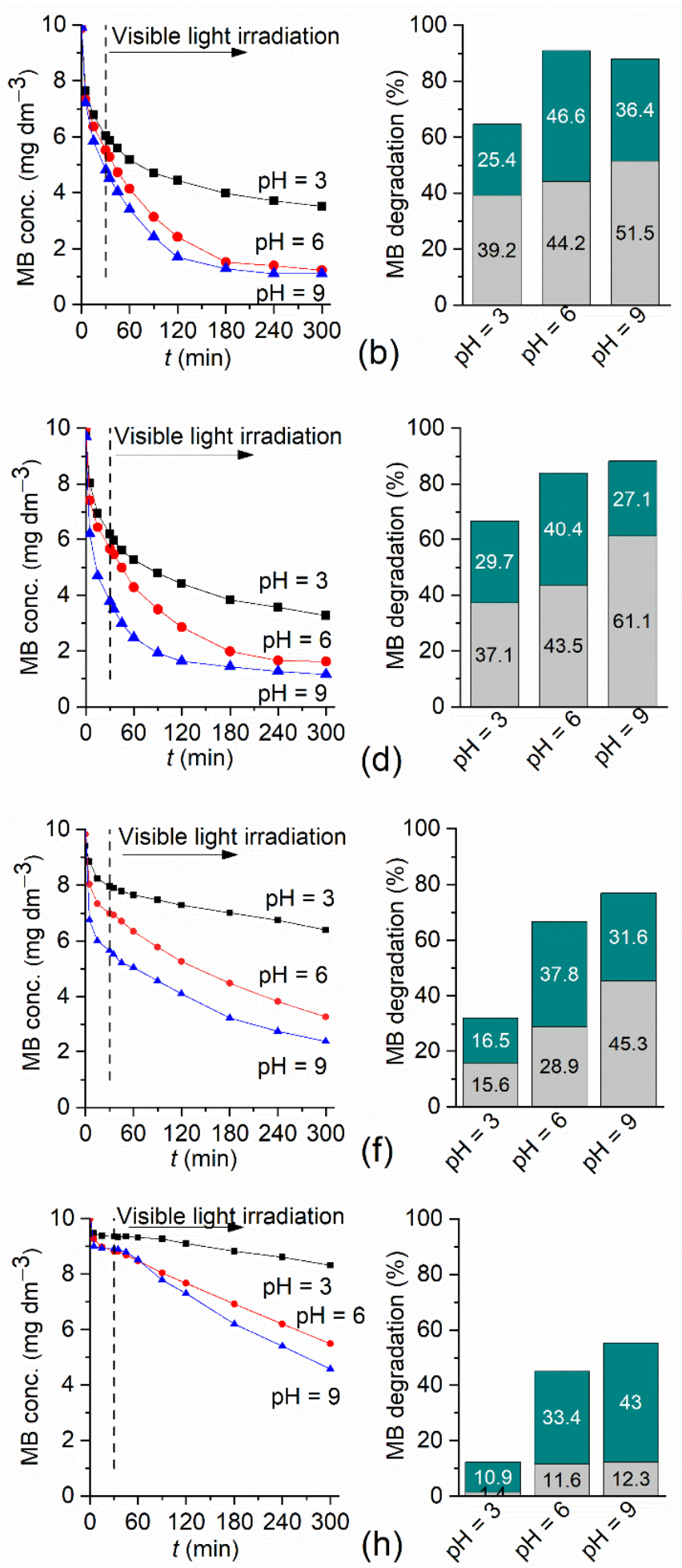

Figure 5. MB photodegradation in the presence of zeolites: (a) SCLI, (b) TCLI, (c) ICLI, (d) RCLI, (e) SKCLI, (f) NaSCLI, (g) $\mathrm{NH}_{4} \mathrm{SCLI}$ and (h) HSCLI. Adsorption and photodegradation phases are represented by bar graphs (gray—adsorption, green—photodegradation). Reaction conditions: $C_{0}=10 \mathrm{mg} \mathrm{dm}^{-3}$ and photocatalyst dosage $10 \mathrm{mg}$. 
To get an insight into the photocatalytic performance of the samples, the iron content was determined in all studied samples. It varies from $0.75 \mathrm{wt}$ \% (ICLI), $0.91 \mathrm{wt}$ \% (SKCLI), 0.98 wt.\% (RCLI), 1.03 wt.\% (SCLI), to 1.06 wt.\% (TCLI). It can be concluded that the photocatalytic activity increases with an increase in the iron content (Figure 6a), and this suggests that the iron species could be responsible for the photocatalytic degradation of MB. The relationship is nearly linear $\left(R^{2}=0.9\right)$.

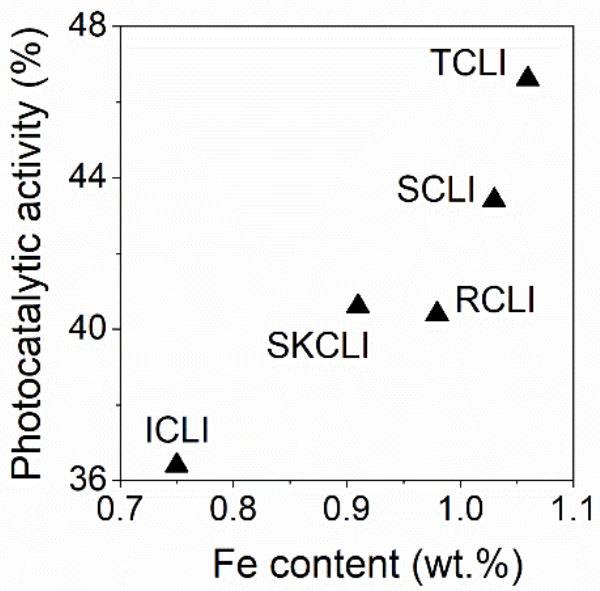

(a)

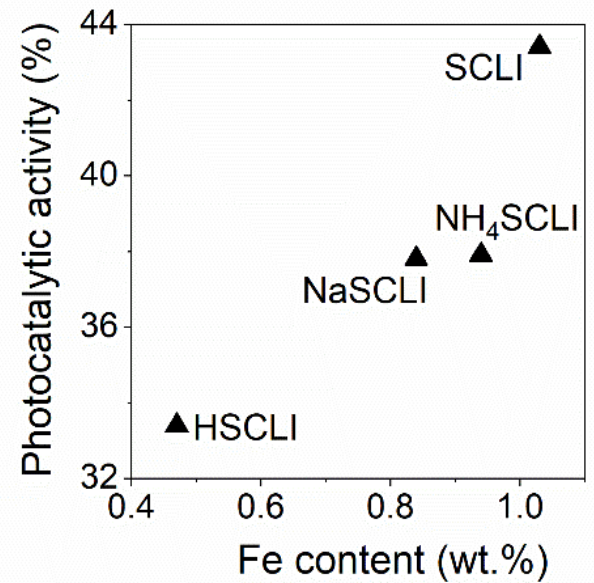

(b)

Figure 6. The influence of iron content on the photocatalytic part of (a) zeolitic tuffs and (b) SCLI and its modified forms at $\mathrm{pH}=6$.

To examine the effect of the specific surface area and the type of cations on photocatalytic activity, three different forms of SCLI (NaSCLI, $\mathrm{NH}_{4} \mathrm{SCLI}$, and HSCLI) were tested in the MB photodegradation. HSCLI has the highest specific surface area; however, the conversion of SCLI to HSCLI led to Fe leaching (the Fe content decreased from 1.03 to 0.47 wt.\%), which caused a decrease in photocatalytic activity under visible light (Figure 6b). The total degradation rate decreased from $70 \%$ (SCLI) to $45 \%$ (Figure 5). The conversion of SCLI to NaSCLI and $\mathrm{NH}_{4}$ SCLI led to a decrease in the Fe content $(0.84$ and 0.94 wt.\%, respectively), and total $\mathrm{MB}$ degradation did not change significantly $(66 \%$ at $\mathrm{pH}=6)$. It can be noted that the presented results correlate well with very recently published results for photocatalytic degradation of rhodamine B [28]. Degradation was ascribed to the presence of Fe impurities in the zeolite tuff. It was also reported that the surface content of Fe should be larger than 0.3 at.\% for photocatalytic activity. The Fe-oxygen species as active sites have been considered photocatalyst nanodots [28]. Moreover, Alvarez-Aguiñaga et al. found that natural clinoptilolite is an effective photocatalyst for the degradation of caffeine-organic aromatic molecules [41]. Small quantities of Fe (1.2 wt.\%) were suggested to be responsible for an almost complete decomposition (99\%) of caffeine after $4 \mathrm{~h}$ under UV irradiation. Moreover, iron-rich minerals have also been reported to exhibit photocatalytic activity in the degradation of textile dyes [42-44].

In order to analyze the MB degradation mechanism, UV-Vis spectra obtained at the end of photocatalytic reaction were analyzed by the deconvolution method given by Marban et al. [45]. The method enabled evaluation of intermediates of the MB photodegradation.

Figure 7 shows the representative spectrum obtained by deconvolution. The peaks associated with $\mathrm{MB}$ are noticeable in the visible region at $664 \mathrm{~nm}$ and can be ascribed to the MB monomer (i.e., a conjugate system formed connection of two dimethylamine substituted aromatic rings via $\mathrm{N}$ and $\mathrm{S}$ ) with a small shoulder at $612 \mathrm{~nm}$, which is due to the MB dimer [46,47]. Two additional peaks observed in the ultraviolet region (located at 245 and $292 \mathrm{~nm}$ ) correspond to substituted benzene rings [46,47]. According to the literature data, the main mechanism pathway includes demethylation of $\mathrm{MB}$, which proceeds through formation of intermediate species Azure B (648-654 nm), Azure A (620-634 nm), Azure C (608-612 nm), and Thionine $(603 \mathrm{~nm})[45,48]$. The Gaussian peaks at $~ 668 \mathrm{~nm}$ (red), 
$\sim 648 \mathrm{~nm}$ (azure), and $\sim 623 \mathrm{~nm}$ (light blue) are present in all spectra and can be ascribed to $\mathrm{MB}$, Azure B, and Azure A, respectively. The difficulty of ascribing the degradation products based on UV-vis spectra is increased since Azure A and B contain the same peaks. The solution was solved by taking into account that the ratio between peaks at absorbance of the peak at $\sim 650 \mathrm{~nm}$ to the absorbance of the peak at $609-614 \mathrm{~nm}$ is 1.15 for azure B, and 0.34 , for azure A [45]. Hence, an estimation of the content of the two products could be made. The fact that similar degradation products were registered for all tested samples supports the suggestion that the iron species present in all zeolite samples are responsible for $\mathrm{MB}$ degradation. Similar results were reported for commercial $\mathrm{TiO}_{2}[45,48]$ and natural manganese oxides $[49,50]$.

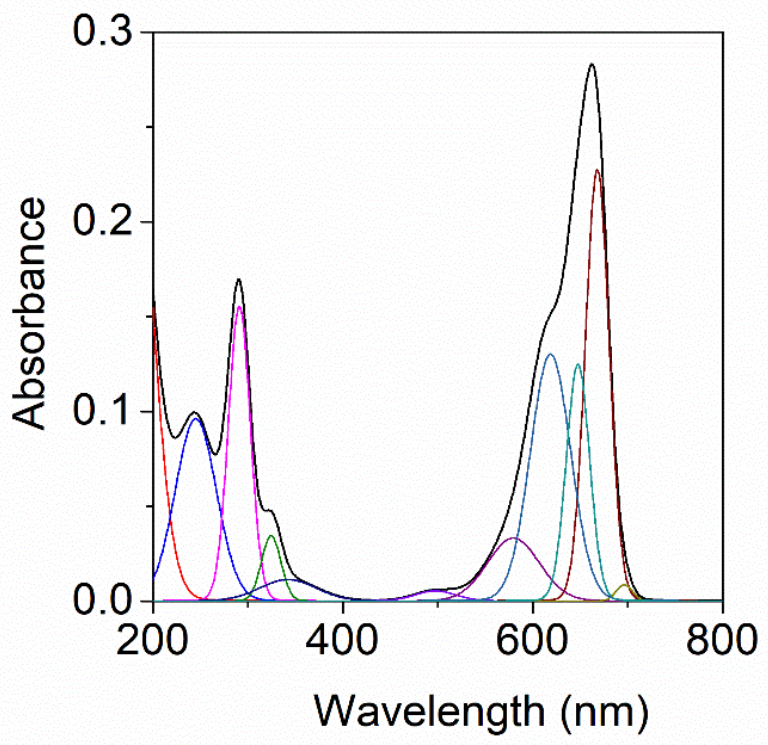

Figure 7. Representative UV-Vis spectrum of SCLI obtained by Gaussian deconvolution at the end of the photocatalytic reaction at $\mathrm{pH}=6$.

Taking these results into account, it can be concluded that MB degradation could be attributed to photooxidation and demethylation of the parent MB molecule, which is possibly followed by further fragmentation and opening of the aromatic ring. We note here that for a more explicit elucidation, an in-depth analysis using mass analyses of degradation products should be made.

\subsubsection{Kinetic Study of the MB Photocatalytic Process}

The data obtained from the photodegradation of MB in the presence of zeolites were evaluated by the Langmuir-Hinshelwood (LH) model, the most commonly used kinetic model for the description of the kinetics of heterogeneous photocatalytic processes that involves both adsorption and photocatalytic phases. The LH model follows the pseudo first-order kinetics, which is expressed as:

$$
\ln \left(C_{0} / C\right)=\mathrm{k}_{\mathrm{app}} \times t
$$

where $C_{0}$ and $C$ are the initial $\mathrm{MB}$ concentration and $\mathrm{MB}$ concentration at time $t\left(\mathrm{mg} \mathrm{dm}^{-3}\right)$, respectively, whereas $k_{\mathrm{ppp}}$ is the apparent rate constant of pseudo-first-order photodegradation reaction $\left(\mathrm{min}^{-1}\right)$.

The value of $k_{\text {app }}$ can be calculated from the slopes of the plots $\ln \left(C_{0} / C_{\mathrm{t}}\right)$ vs $t$. The results are listed in Table 4 . These data indicate that: (a) $k_{\text {app }}$ significantly increased by increasing $\mathrm{pH}$ from 3 to 6 for all tested samples, and (b) there are no noticeable changes with further increases of $\mathrm{pH}$ up to 9, confirming that at $\mathrm{pH}=6$, the photodegradation reaction of $\mathrm{MB}$ proceeds at the highest rate. At $\mathrm{pH}=6$, the values of $k_{\mathrm{app}}$ ranged from 0.0035 to $0.0064 \mathrm{~min}^{-1}$ showing that the $\mathrm{MB}$ photocatalytic degradation proceeded twice 
as fast in the presence of TCLI in comparison to SCLI. This fact could be attributed to a synergistic effect of the high Fe content in TCLI and its high specific surface area. In addition, by comparing the values of $k_{\text {app }}$ for SCLI and its modified forms, MB degradation proceeded the slowest in the presence of HSCLI. The obtained value is similar to that very recently reported by Sydorchukv et al. for the degradation of rhodamine B in the presence of the $\mathrm{H}$-form of natural clinoptilolite [28], as well as for the decomposition of caffeine $\left(0.0073 \mathrm{~min}^{-1}\right)$ reported by Alvarez-Aguiñaga et al. [41].

Table 4. Apparent rate constants $\left(k_{\mathrm{app}}\right)$ calculated by Langmuir-Hinshelwood model.

\begin{tabular}{|c|c|c|c|}
\hline Sample & $\mathrm{pH}=3$ & $\mathrm{pH}=6$ & $\mathrm{pH}=9$ \\
\hline \multicolumn{4}{|c|}{ SCLI } \\
\hline$k_{\mathrm{app}}, \min ^{-1}$ & 0.0011 & 0.0035 & 0.0036 \\
\hline$R^{2}$ & 0.9813 & 0.9996 & 0.9980 \\
\hline \multicolumn{4}{|c|}{ TCLI } \\
\hline$k_{\mathrm{app}}, \min ^{-1}$ & 0.0024 & 0.0064 & 0.0066 \\
\hline$R^{2}$ & 0.9944 & 0.9986 & 0.9904 \\
\hline \multicolumn{4}{|c|}{ ICLI } \\
\hline$k_{\mathrm{app}}, \min ^{-1}$ & 0.0017 & 0.0037 & 0.0038 \\
\hline$R^{2}$ & 0.9978 & 0.9979 & 0.9994 \\
\hline \multicolumn{4}{|c|}{ RCLI } \\
\hline$k_{\mathrm{app}}, \min ^{-1}$ & 0.0027 & 0.0052 & 0.0054 \\
\hline$R^{2}$ & 0.9951 & 0.9883 & 0.9866 \\
\hline \multicolumn{4}{|c|}{ SKCLI } \\
\hline$k_{\mathrm{app}}, \min ^{-1}$ & 0.0014 & 0.0040 & 0.0044 \\
\hline$R^{2}$ & 0.9987 & 0.9937 & 0.9977 \\
\hline \multicolumn{4}{|c|}{ NaSCLI } \\
\hline$k_{\mathrm{app}}, \min ^{-1}$ & 0.0009 & 0.0029 & 0.0034 \\
\hline$R^{2}$ & 0.9967 & 0.9988 & 0.9969 \\
\hline \multicolumn{4}{|c|}{$\mathrm{NH}_{4} \mathrm{SCLI}$} \\
\hline$k_{\mathrm{app}}, \min ^{-1}$ & 0.0007 & 0.0028 & 0.0024 \\
\hline$R^{2}$ & 0.9863 & 0.9996 & 0.9999 \\
\hline \multicolumn{4}{|c|}{ HSCLI } \\
\hline$k_{\mathrm{app}}, \min ^{-1}$ & 0.0004 & 0.0017 & 0.0024 \\
\hline$R^{2}$ & 0.9914 & 0.9994 & 0.9995 \\
\hline
\end{tabular}

\subsubsection{Recyclability of the Zeolite-Based Photocatalyst}

Recyclability is one of the most important features of a catalyst. Accordingly, the recyclability tests of TCLI (three consecutive reaction cycles) were performed in this work.

It can be seen that TCLI loses photocatalytic efficiency to some extent through subsequent tests (Figure 8). However, PXRD and SEM analyses confirmed stability of the reused TCLI: (a) crystallinity of the spent The TCLI only slightly changed, and (b) morphology properties were preserved (Figure 9).

The MB adsorption rate in the initial dark phase decreased slightly, indicating that some of the active sites were blocked. However, TCLI is still photocatalytically active. The total degradation of $\mathrm{MB}$ decreased from 91 to $69 \%$ after three reaction cycles. 

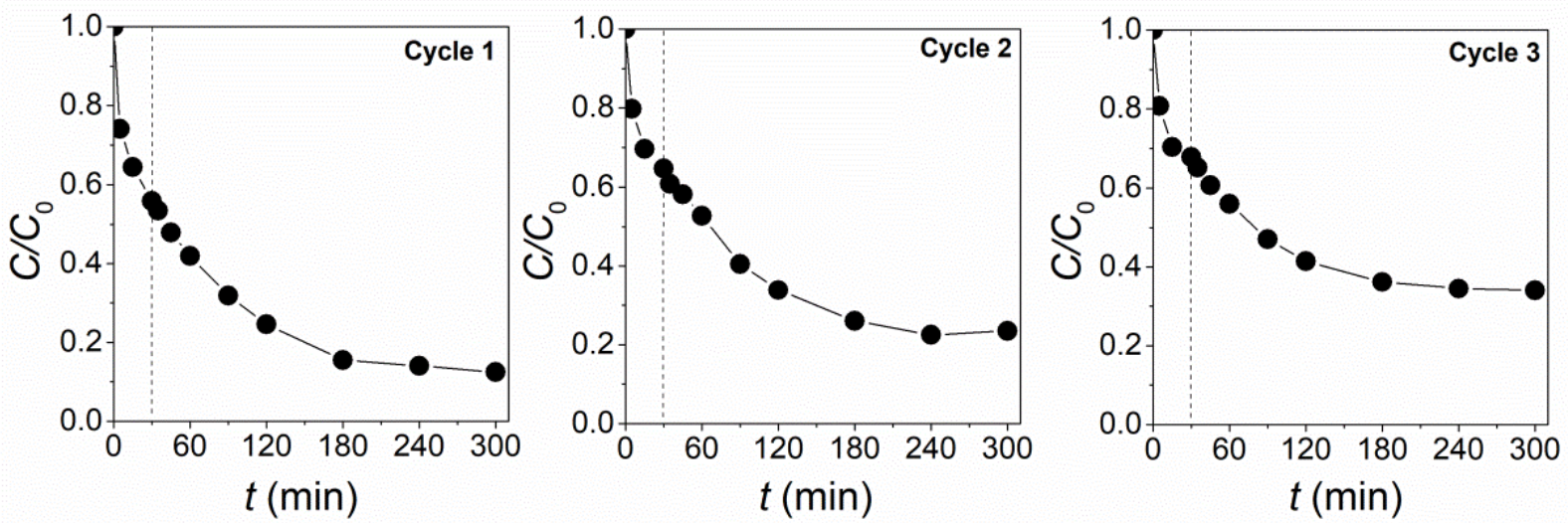

Figure 8. Recyclability of the photocatalyst in the MB photodegradation. Reaction conditions: $C_{0}=10 \mathrm{mg} \mathrm{dm}^{-3}$, photocatalyst dosage $=0.2 \mathrm{~g} \mathrm{dm}^{-3}, \mathrm{pH}=6$, and $t=300 \mathrm{~min}$.

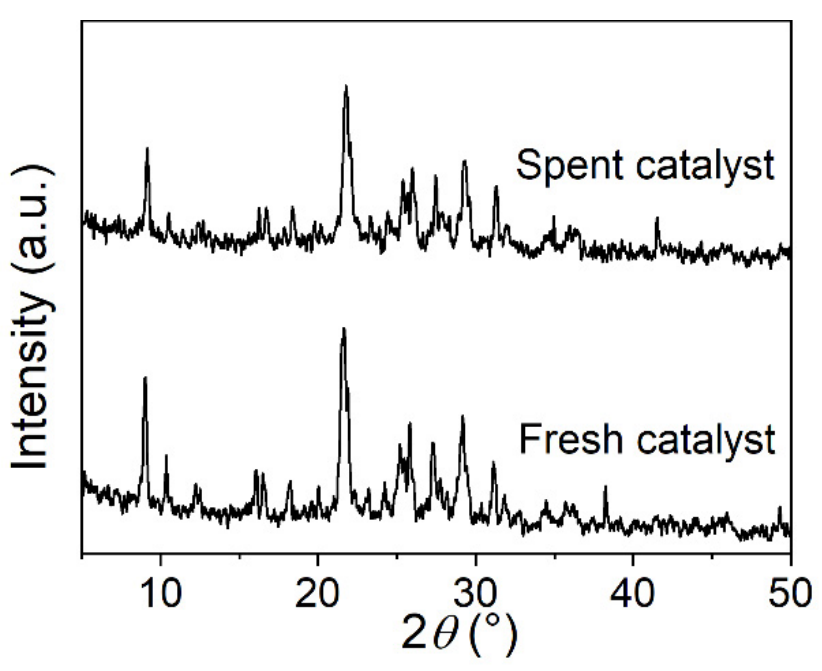

(a)

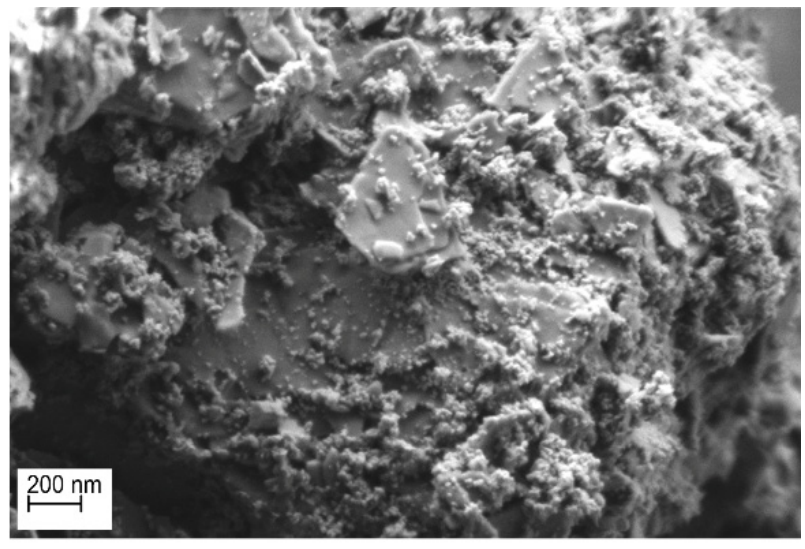

(b)

Figure 9. (a) PXRD patterns of fresh and spent photocatalyst and (b) SEM image of photocatalyst at the end of photocatalytic process.

\section{Materials and Methods}

\subsection{Materials}

The examined zeolitic tuffs were from the following regions and deposits: (a) SerbiaSlanci (SCLI), (b) Turkey-Gördes (TCLI), (c) Iran-Semnam (ICLI), (d) Romania-Baia Mare (RCLI), and (e) Slovakia-Nižný Hrabovec (SKCLI).

Prior to all experiments, samples were sieved to obtain the particle population having the size in the range 63 and $125 \mu \mathrm{m}$ mesh. Then, the samples were washed with deionized water, dried at $105^{\circ} \mathrm{C}$ overnight, and tested without any additional treatments.

In order to gain insight into the influence of metal cations present in the CLI lattice on photocatalytic activity, SCLI was converted into $\mathrm{Na}-, \mathrm{NH}_{4}-$ and $\mathrm{H}-$ forms by the following procedures: (1) ion exchange using $2 \mathrm{M} \mathrm{NaCl}$ at $70{ }^{\circ} \mathrm{C}$ and $1 \mathrm{M} \mathrm{NH}_{4} \mathrm{CH}_{3} \mathrm{COOH}$ at $25^{\circ} \mathrm{C}$ to obtain NaSCLI and $\mathrm{NH}_{4} \mathrm{SCLI}$, respectively and (2) step-wise dealumination of the SCLI with $\mathrm{HCl}$ using the procedure reported by Garcia-Basabe et al. [35] to obtain HSCLI.

All used chemicals were of analytical grade, and Milli-Q deionized water was utilized for the preparation of all aqueous solutions.

Methylene blue was chosen as a typical cationic dye widely used in the textile industry. Basic characteristics of MB are listed in Table 5. 
Table 5. Characteristics of model dye methylene blue (MB).

\begin{tabular}{c}
\hline Property \\
IUPAC name \\
Chemical structure \\
Molecular formula \\
Molecular weight, g mol ${ }^{-1}$ \\
Type of dye \\
Solubility in water
\end{tabular}

\subsection{Characterization}

The mineral composition of the zeolitic tuffs was determined by powder X-ray diffraction analysis (PXRD) using an APD2000 Ital Structure diffractometer $\left(\mathrm{CuK}_{\alpha}\right.$ radiation, $\lambda=0.15418 \mathrm{~nm}$, generated at $38 \mathrm{kV}$ and $28 \mathrm{~mA}$ ). Scans were performed in the $2 \theta$ range $5-50^{\circ}$ with a step of $0.02^{\circ}$ and integrating time $1 \mathrm{~s}$ per step. Semi-quantitative PXRD analysis was conducted using the Rietveld refinement and the Topas-Academic v.4 software package (Bruker AXS, Karlsruhe, Germany) [51].

Cation exchange capacity (CEC) of the zeolitic tuffs was determined using a standard procedure based on the ion-exchange reaction with $1 \mathrm{M} \mathrm{NH}_{4} \mathrm{CH}_{3} \mathrm{COOH}$ solution at room temperature for $24 \mathrm{~h}$ [52]. Concentration of exchangeable cations $\left(\mathrm{Na}^{+}, \mathrm{K}^{+}, \mathrm{Ca}^{2+}\right.$, and $\mathrm{Mg}^{2+}$ ) was measured in filtrates, and CEC value was expressed in $\mathrm{mmol}$ of $\mathrm{M}^{+}$per $100 \mathrm{~g}$ of the sample.

Surface morphology was observed by scanning electron microscopy (SEM). SEM images were collected on a Carl Zeiss Supra ${ }^{\mathrm{TM}}$ 3VP field-emission gun scanning electron microscope (FEG-SEM, Carl Zeiss AG, Oberkochen, Germany), operating at $1 \mathrm{kV}$.

Thermal behavior was examined by simultaneous thermogravimetric (TGA) and differential thermal analysis (DTA). The measurements were performed using an SDT Q-600 instrument (TA Instruments, New Castle, DE, USA). A sample (about $10 \mathrm{mg}$ ) was heated in opened alumina cups $(90 \mu \mathrm{L})$ from room temperature to $800^{\circ} \mathrm{C}$ at a heating rate of $10^{\circ} \mathrm{C} \mathrm{min}-1$ under synthetic air $\left(100 \mathrm{~mL} \mathrm{~min}^{-1}\right)$. The collected data were evaluated with TA-Universal Analysis software.

Textural properties of samples were analyzed by the adsorption/desorption of nitrogen at $-196^{\circ} \mathrm{C}$ using an automatic sorption analyzer (ASAP 2020, Micromeritics Instrument, Norcross, GA, USA). All samples were degassed overnight at $20{ }^{\circ} \mathrm{C}$ under high vacuum before the analysis. The specific surface area $\left(S_{\mathrm{BET}}\right)$ was calculated using the Brunauer, Emmett, Teller (BET) method up to relative pressures $p / p_{0}=0.15$. The total pore volume $\left(V_{\text {tot }}\right)$ was assessed at $p / p_{0}=0.99$. Pore size distribution was analyzed according to the Barrett, Joyner, and Halenda method (BJH) from the adsorption isotherms.

Iron content in the samples was determined in solutions after microwave digestion of the samples. The digestion was performed using a close microwave oven system (CEM Corporation Mars 6, Matthews, NC, USA), and the digestion procedure was chosen in agreement with manufacturer recommendations [53]. Briefly, about $0.5 \mathrm{~g}$ of sample was placed into the digestion vessel, and then a mixture of concentrated acids containing $5 \mathrm{~cm}^{3}$ 
of $\mathrm{HNO}_{3}, 4 \mathrm{~cm}^{3} \mathrm{HCl}$ and $2 \mathrm{~cm}^{3}$ of $\mathrm{HF}$ was added carefully. The vessels were capped, put into the microwave digestion system, digested by increasing the temperature to $210^{\circ} \mathrm{C}$ for $30 \mathrm{~min}$, and left for $15 \mathrm{~min}$ at a pressure of $800 \mathrm{psi}(900 \mathrm{~W})$ to complete digestion. The obtained digested samples were diluted with ultrapure water to a final volume of $50 \mathrm{~cm}^{3}$, and the concentration of iron was measured by atomic absorption spectroscopy (Varian SpectrAA, 55B). Measurement accuracy was $\pm 2 \%$. All measurements were done in accordance with manual recommendations.

\subsection{Photocatalytic Tests}

Photodegradation tests were carried out using a batch reactor system equipped with a $50 \mathrm{~cm}^{3}$ Pyrex glass cell and by a circulating water jacket to keep the temperature constant at $25{ }^{\circ} \mathrm{C}$ during the reaction. A blank solution contained MB without the photocatalyst. All tests were done at atmospheric pressure and in triplicate. An average value was represented.

In a typical photocatalytic reaction, suspension containing water solution of $\mathrm{MB}$ $\left(C_{0}=10 \mathrm{mg} \mathrm{dm}^{-3}\right)$ and photocatalyst in the concentration of $0.2 \mathrm{~g} \mathrm{dm}^{-3}$ at different $\mathrm{pH}$ $(\mathrm{pH}=3,6$, or 9) was continuously stirred by a magnetic stirrer for $30 \mathrm{~min}$ to achieve an adsorption/desorption equilibrium. The initial $\mathrm{pH}$ was adjusted by the addition of either $0.1 \mathrm{M} \mathrm{HCl}$ or $0.1 \mathrm{M} \mathrm{NaOH}$ solutions. Then, the suspension was irradiated for $300 \mathrm{~min}$ under an Osram Ultra Vitalux lamp (300 W) serving as a visible light source, positioned $10 \mathrm{~cm}$ above the photocatalytic reactor.

The concentration of MB was measured colorimetrically at $\lambda=664 \mathrm{~nm}$ using UV/VIS spectroscopy (Lambda 365 spectrophotometer, Perkin Elmer). The concentration changes of MB followed Lambert-Beer's law, and the degradation extent was calculated from the absorbance change of the $\mathrm{MB}$ solution by the following equation:

$$
\text { MB degradation }(\%)=\left[\left(A_{0}-A_{\mathrm{t}}\right) / A_{0}\right] \times 100
$$

where $A_{0}$ and $A_{\mathrm{t}}$ represents the initial absorbance and the absorbance of $\mathrm{MB}$ at time $t$, respectively. The deconvolution of the spectra was done with PeakFit v4.06 software using Gaussian peak function (Systat Software, San Jose, CA, USA). A linear baseline was applied to the spectra from the lowest point in the UV range to the lowest point in the $>750 \mathrm{~nm}$ part.

Recyclability of the Photocatalyst

TCLI photocatalyst was chosen for the recyclability test as the catalyst with the highest photocatalytic activity. Recyclability was tested in three consecutive reaction cycles. After separation from the suspension, the photocatalyst was regenerated after each cycle by washing with deionized water followed by drying at room temperature and calcination at $500{ }^{\circ} \mathrm{C}$ in air for $1 \mathrm{~h}$. The regenerated photocatalyst was analyzed by PXRD and SEM prior to reuse.

\section{Conclusions}

The present results show that zeolitic tuffs, rich in clinoptilolite phase, can be applied in the photodegradation of cationic organic dyes, such as methylene blue, under environmentally friendly conditions: visible light, atmospheric pressure, and room temperature. Photodegradation efficiency depends on the origin of the zeolite. In this study, the best performance was found for the zeolitic tuff from Turkey-Gördes deposit. This can be attributed to the highest content of Fe (1.06 wt.\%) and the highest specific surface area $\left(45.1 \mathrm{~m}^{2} \mathrm{~g}^{-1}\right)$, as well as the highest share of mesopores that allow diffusion of MB.

The total degradation rate for the studied tuffs varied from 70 to $91 \%$ (for $C_{0}=10 \mathrm{mg}$ $\mathrm{MB} \mathrm{dm}{ }^{-3}, 0.2 \mathrm{~g} \mathrm{CLI} \mathrm{dm}^{-3}$, for $300 \mathrm{~min}$ ). The best activity was found at $\mathrm{pH}=6$. The photodegradation follows the Langmuir-Hinshelwood kinetic model.

Conversion of SCLI to NaSCLI and $\mathrm{NH}_{4} \mathrm{SCLI}$ did not significantly affect the total degradation rate of $\mathrm{MB}$, whereas conversion to HSCLI decreased the activity-most probably due to Fe leaching during the conversion procedure. 
Recyclability tests demonstrated good recyclability and stability of the CLI after three repeated photodegradation reactions. Total MB degradation was $69 \%$ after three cycles.

Considering all presented results, the zeolitic tuffs from different regions can be considered as a prospective candidate for photocatalytic treatment of textile wastewater.

Author Contributions: Conceptualization and methodology, J.P., A.Š. and N.R.; formal analysis, J.P., A.Š. and M.O.; writing —original draft preparation, J.P., A.S.s. and N.R.; writing—review and editing, N.R., N.N.T. and N.Z.L.; visualization, J.P.; project administration, N.R.; funding acquisition, N.R. and N.Z.L. All authors have read and agreed to the published version of the manuscript.

Funding: This research was funded by the Ministry of Education, Science and Technological Development of the Republic of Serbia (Contract No. 451-03-9/2022-14/200287 and 451-03-9/2022-14/200135) and the Slovenian Research Agency (research programs P1-0021 and P1-0134).

Data Availability Statement: The data presented in this study are available on request from the corresponding author.

Conflicts of Interest: The authors declare no conflict of interest.

\section{References}

1. Li, W.; Mu, B.; Yang, Y. Feasibility of industrial-scale treatment of dye wastewater via bioadsorption technology. Bioresour. Technol. 2019, 277, 157-170. [CrossRef] [PubMed]

2. Benkhaya, S.; M'rabet, S.; El Harfi, A. A review on classifications, recent synthesis and applications of textile dyes. Inorg. Chem. Commun. 2020, 115, 107891. [CrossRef]

3. Tkaczyk, A.; Mitrowska, K.; Posyniak, A. Synthetic organic dyes as contaminants of the aquatic environment and their implications for ecosystems: A review. Sci. Total Environ. 2020, 717, 137222. [CrossRef] [PubMed]

4. Rauf, M.A.; Ashraf, S.S. Fundamental principles and application of heterogeneous photocatalytic degradation of dyes in solution. Chem. Eng. J. 2009, 151, 10-18. [CrossRef]

5. Neelgund, G.M.; Oki, A. ZnO conjugated graphene: An efficient sunlight driven photocatalyst for degradation of organic dyes. Mater. Res. Bull. 2020, 129, 110911. [CrossRef]

6. Motahari, F.; Mozdianfard, M.R.; Soofivand, F.; Salavati-Niasari, M. NiO nanostructures: Synthesis, characterization and photocatalyst application in dye wastewater treatment. RSC Adv. 2014, 4, 27654-27660. [CrossRef]

7. Dariani, R.S.; Esmaeili, A.; Morteyaali, A.; Dehghanpour, S. Photocatalytic reaction and degradation of methylene blue on TiO 2 nano-sized particles. Optik 2016, 74, 7143-7154. [CrossRef]

8. Kim, S.P.; Choi, M.Y.; Choi, H.C. Photocatalytic activity of $\mathrm{SnO}_{2}$ nanoparticles in methylene blue degradation. Mater. Res. Bull. 2016, 74, 85-89. [CrossRef]

9. Imran, M.; Abutaleb, A.; Ali, A.A.; Ahamad, T.; Ansari, A.R.; Shariq, M.; Lolla, D.; Khan, A. UV light enabled photocatalytic activity of $\alpha-\mathrm{Fe}_{2} \mathrm{O}_{3}$ nanoparticles synthesized via phase transformation. Mater. Lett. 2020, 258, 136748. [CrossRef]

10. Maučec, D.; Šuligoj, A.; Ristić, A.; Dražić, G.; Pintar, A.; Novak Tušar, N. Titania versus zinc oxide nanoparticles on mesoporous silica supports as photocatalysts for removal of dyes from wastewater at neutral pH. Catal. Today 2018, 310, 32-41. [CrossRef]

11. Hass Caetano Lacerda, E.; Casanova Monteiro, F.; Regina Kloss, J.; Fujiwara, S.T. Bentonite clay modified with $\mathrm{Nb}_{2} \mathrm{O}_{5}$ : $\mathrm{An}$ efficient and reused photocatalyst for the degradation of reactive textile dye. J. Photoch. Photobiol. A 2020, 388, 112084. [CrossRef]

12. Hu, G.; Yang, J.; Duan, X.; Farnood, R.; Yang, C.; Yang, J.; Liu, W.; Liu, Q. Recent developments and challenges in zeolite-based composite photocatalysts for environmental applications. Chem. Eng. J. 2021, 417, 129209. [CrossRef]

13. Ramírez-Aparicio, J.; Samaniego-Benítez, J.E.; Murillo-Tovar, M.A.; Benítez-Benítez, J.L.; Munoz-Sandoval, E.; García-Betancourt, M.L. Removal and surface photocatalytic degradation of methylene blue on carbon nanostructures. Diam. Relat. Mater. 2021, $119,108544$. [CrossRef]

14. Derikvandi, H.; Nezamzadeh-Ejhieh, A. A comprehensive study on electrochemical and photocatalytic activity of $\mathrm{SnO}_{2-}$ ZnO/clinoptilolite nanoparticles. J. Mol. Catal. A Chem. 2017, 426, 158-169. [CrossRef]

15. Tedla, H.; Díaz, I.; Kebede, T.; Taddesse, A.M. Synthesis, characterization and photocatalytic activity of zeolite supported $\mathrm{ZnO} / \mathrm{Fe}_{2} \mathrm{O}_{3} / \mathrm{MnO}_{2}$ nanocomposites. J. Environ. Chem. Eng. 2015, 3, 1586-1591. [CrossRef]

16. Badvi, K.; Javanbakht, V. Enhanced photocatalytic degradation of dye contaminants with $\mathrm{TiO}_{2}$ immobilized on ZSM-5 zeolite modified with nickel nanoparticles. J. Clean. Prod. 2021, 280, 124518. [CrossRef]

17. Ikhlaq, A.; Fatima, R.; Qazi, U.Y.; Javaid, R.; Akram, A.; Ibn Shamsah, S.; Qi, F. Combined Iron-Loaded Zeolites and Ozone-Based Process for the Purification of Drinking Water in a Novel Hybrid Reactor: Removal of Faecal Coliforms and Arsenic. Catalysts 2021, 11, 373. [CrossRef]

18. Ullah, R.; Liu, C.; Panezai, H.; Gul, A.; Sun, J.; Wu, X. Controlled crystal phase and particle size of loaded-TiO ${ }_{2}$ using clinoptilolite as support via hydrothermal method for degradation of crystal violet dye in aqueous solution. Arab. J. Chem. 2020, 13, 4092-4101. [CrossRef]

19. Godelitsas, A.; Armbruster, T. HEU-type zeolites modified by transition elements and lead. Micropor. Mesopor. Mat. 2003, 61, 3-24. [CrossRef] 
20. Eroglu, N.; Emekci, M.; Athanassiou, C.G. Applications of natural zeolites on agriculture and food production. J. Sci. Food Agric. 2017, 97, 3487-3499. [CrossRef]

21. Behin, J.; Ghadamnan, E.; Kazemian, H. Recent advances in the science and technology of natural zeolites in Iran. Clay Miner. 2019, 54, 131-144. [CrossRef]

22. Serati-Nouri, H.; Jafari, A.; Roshangar, L.; Dadashpour, M.; Pilehvar-Soltanahmadi, Y.; Zarghami, N. Biomedical applications of zeolite-based materials: A review. Mater. Sci. Eng. C 2020, 116, 111225. [CrossRef] [PubMed]

23. Dzinum, H.; Othman, M.H.; Ismail, A.F. Photocatalytic performance of $\mathrm{TiO}_{2} /$ Clinoptilolite: Comparison study in suspension and hybrid photocatalytic membrane reactor. Chemosphere 2019, 228, 241-2498. [CrossRef] [PubMed]

24. Šuligoj, A.; Pavlović, J.; Arčon, I.; Rajić, N.; Novak Tušar, N. SnO $\mathrm{S}_{2}$-containing clinoptilolite as a composite photocatalyst for dyes removal from wastewater under solar light. Catalysts 2020, 10, 253. [CrossRef]

25. Abdollahi, B.; Shakeri, A.; Aber, S.; Bonab, M.S. Simultaneous photodegradation of acid orange 7 and removal of $\mathrm{Pb}^{2+} \mathrm{from}$ polluted water using reusable clinoptilolite- $\mathrm{TiO}_{2}$ nanocomposite. Res. Chem. Intermediat. 2018, 44, 1505-1521. [CrossRef]

26. Bahrami, M.; Nezamzadeh-Ejhieh, A. Effect of the supported ZnO on clinoptilolite nano-particles in the photodecolorization of semi-real sample bromothymol blue aqueous solution. Mater. Sci. Semicon. Proc. 2015, 30, 275-284. [CrossRef]

27. Nezamzadeh-Ejhieh, A.; Zabihi-Mobarakeh, H. Heterogeneous photodecolorization of mixture of methylene blue and bromophenol blue using CuO-nano-clinoptilolite. J. Ind. Eng. Chem. 2014, 20, 1421-1431. [CrossRef]

28. Sydorchukv, V.; Vasylechko, V.; Khyzhun, O.; Gryshchouk, G.; Khalameida, S.; Vasylechko, L. Effect of high-energy milling on the structure, some physicochemical and photocatalytic properties of clinoptilolite. Appl. Catal. A Gen. 2021, 610, 117930. [CrossRef]

29. Dong, X.; Lin, Y.; Ren, G.; Ma, Y.; Zhao, L. Catalytic degradation of methylene blue by Fenton-like oxidation of Ce doped MOF. Colloid. Surf. A 2021, 608, 125578. [CrossRef]

30. Bingül, Z. Determination of affecting parameters on removal of methylene blue dyestuff from aqueous solutions using natural clay: Isotherm, kinetic, and thermodynamic studies. J. Mol. Struct. 2022, 1250, 131729. [CrossRef]

31. Khnifira, M.; El Hamidi, S.; Sadiq, M.; Şimşek, S.; Kaya, S.; Barka, N.; Abdennouri, M. Adsorption mechanisms investigation of methylene blue on the (001) zeolite $4 \mathrm{~A}$ surface in aqueous medium by computational approach and molecular dynamics. Appl. Surf. Sci. 2022, 572, 151381. [CrossRef]

32. Wainwright, M.; Crossley, K.B. Methylene Blue-A Therapeutic Dye for All Seasons? J. Chemother. 2002, 14, 431-443. [CrossRef] [PubMed]

33. Khan, I.; Saeed, K.; Zekker, I.; Zhang, B.; Hendi, A.H.; Ahmad, A.; Ahmad, S.; Zada, N.; Ahmad, H.; Shah, L.A.; et al. Review on Methylene Blue: Its Properties, Uses, Toxicity and Photodegradation. Water 2022, 14, 242. [CrossRef]

34. Treacy, M.M.J.; Higgins, J.B. Collection of Simulated XRD Powder Patterns for Zeolites, 1st ed.; Elsevier: Amsterdam, The Netherlands, 2001; pp. 186-187. ISBN 9780080529349.

35. Garcia-Basabe, Y.; Rodriguez-Iznaga, I.; de Menorval, L.-C.; Llewellyn, P.; Maurin, G.; Lewis, D.W.; Binions, R.; Autie, M.; Ruiz-Salvador, A.R. Step-wise dealumination of natural clinoptilolite: Structural and physicochemical characterization. Micropor. Mesopor. Mater. 2010, 135, 187-196. [CrossRef]

36. Pavlović, J.; Popova, M.; Mihalyi, R.M.; Mazaj, M.; Mali, G.; Kovač, J.; Lazarova, H.; Rajić, N. Catalytic activity of SnO $2-$ and $\mathrm{SO}_{4} / \mathrm{SnO}_{2}$-containing clinoptilolite in the esterification of levulinic acid. Micropor. Mesopor. Mater. 2019, 27, 10-18. [CrossRef]

37. Farías, T.; Ruiz-Salvador, A.R.; Velazco, L.; de Ménorval, L.C.; Rivera, A. Preparation of natural zeolitic supports for potential biomedical applications. Mater. Chem. Phys. 2009, 118, 322-328. [CrossRef]

38. Kouvelos, E.; Kesore, K.; Steriotis, T.; Grigoropoulou, H.; Bouloubasi, D.; Theophilou, N.; Tzintzos, S.; Kanelopoulos, N. High pressure $\mathrm{N}_{2} / \mathrm{CH}_{4}$ adsorption measurements in clinoptilolites. Micropor. Mesopor. Mater. 2007, 99, 106-111. [CrossRef]

39. De Souza Macedo, J.; da Costa Júnior, N.B.; Almeida, L.E.; da Silva Vieira, E.F.; de Fátima Gimenez, I.; Carreño, N.L.V.; Barreto, L.S. Kinetic and calorimetric study of the adsorption of dyes on mesoporous activated carbon prepared from coconut coir dust. J. Colloid. Interf. Sci. 2006, 298, 515-522. [CrossRef]

40. Li, H.; Liu, L.; Cui, J.; Cui, J.; Wang, F.; Zhang, F. High-efficiency adsorption and regeneration of methylene blue and aniline onto activated carbon from waste edible fungus residue and its possible mechanism. RSC Adv. 2020, 10, 14262-14273. [CrossRef]

41. Alvarez-Aguiñaga, E.A.; Elizade-González, M.P.; Sabinas-Hernández, S.A. Unpredicted photocatalytic activity of clinoptilolitemordenite natural zeolite. RSC Adv. 2020, 10, 39251-39260. [CrossRef]

42. Cheng, M.; Song, W.; Ma, W.; Chen, C.; Zhao, J.; Lin, J.; Zhu, H. Catalytic activity of iron species in layered clays for photodegradation of organic dyes under visible irradiation. Appl. Catal. B Environ. 2008, 77, 355-363. [CrossRef]

43. Wang, Z.; Huang, L.; Du, L.; Sheng, H.; Lv, B. Photocatalysis by iron-rich montmorillonite for the treatment of dyeing wastewater. Chem. Eng. Comm. 2010, 197, 1048-1056. [CrossRef]

44. Pereira, M.C.; Oliveira, L.C.A.; Murad, E. Iron oxide catalysts: Fenton and Fentonlike reactions-A review. Clay Miner. 2012, 47, 285-302. [CrossRef]

45. Marbán, G.; Vu, T.T.; Valdés-Solís, T. A simple visible spectrum deconvolution technique to prevent the artefact induced by the hypsochromic shift from masking the concentration of methylene blue in photodegradation experiments. Appl. Catal. A Gen. 2011, 402, 218-223. [CrossRef]

46. Rauf, M.A.; Meetani, M.A.; Khaleel, A.; Ahmed, A. Photocatalytic degradation of Methylene Blue using a mixed catalyst and product analysis by LC/MS. Chem. Eng. J. 2010, 157, 373-378. [CrossRef]

47. Mondal, S.; Reyes, M.E.; Pal, U. Plasmon induced enhanced photocatalytic activity of gold loaded hydroxyapatite nanoparticles for methylene blue degradation under visible light. RSC Adv. 2017, 7, 8633. [CrossRef] 
48. Moustakas, N.G.; Kontos, A.G.; Likodimos, F.; Katsaros, F.; Boukos, N.; Tsoutsou, D.; Dimoulas, A.; Romanos, G.E.; Dionysoou, D.D.; Falaras, P. Inorganic-organic core-shell titania nanoparticles for efficient visible light activated photocatalysis. Appl. Catal. B Environ. 2013, 130-131, 14-24. [CrossRef]

49. Zaied, M.; Peulon, S.; Bellakhal, N.; Desmazières, B.; Chaussé, A. Studies of N-demethylation oxidative and degradation of methylene blue by thin layers of birnessite electrodeposited onto $\mathrm{SnO}_{2}$. Appl. Catal. B Environ. 2011, 101, 441-450. [CrossRef]

50. Zhou, S.; Du, Z.; Li, X.; Zhang, Y.; He, Y.; Zhang, Y. Degradation of methylene blue by natural manganese oxides: Kinetics and transformation products. R. Soc. Open Sci. 2019, 6, 190351. [CrossRef] [PubMed]

51. Coelho, A. TOPAS Academic 4.1 Coelho Software; Coelho Software: Brisbane, Australia, 2007.

52. Ming, D.W.; Dixon, J.B. Quantitative determination of clinoptilolite in soils by a cation-exchange capacity method. Clay Clay Miner. 1987, 35, 463-468. [CrossRef]

53. CEM, MARS 6, Microwave Acid Digestion, Method Note Compendium. 2019. Available online: https://cem.com/en/mars-6method-note-compendium (accessed on 28 January 2022). 